\title{
Development of a Two-Layer Porous Scafifold Based on Porcine Nasal Septal Cartiliage for Orthopedics
}

DOI: $10.17691 \mathrm{stm} 2021.13 .4 .05$

Received May 17, 2021

N.Yu. Ignatieva, DSC, Associate Professor, Chemical Faculty';

O.L. Zakharkina, Researcher?;

E.A. Sergeeva, PhD, Senior Researcher";

N.B. Serezhnikova, PhD, Senior Researcher";

A.L. Faizullin, Junior Researcher";

A.B. Shekhter, MD, DSc, Chief Researcher, Laboratory of Experimental Morphology and Biobank, Institute for Regenerative Medicine ${ }^{4}$

Lomonosov Moscow State University, 1, bld. 3 Leninskiye Gory, Moscow, 119991, Russia;

2Institute of Photonic Technologies of Federal Scientific Research Center "Crystallography and Photonics" of the Russian Academy of Sciences, 2 Pionerskaya St., Moscow, Troitsk, 108840, Russia;

${ }^{3}$ Federal Research Center Institute of Applied Physics of the Russian Academy of Sciences, 46 Ulyanova St., Nizhny Novgorod, 603950, Russia;

${ }^{4}$ I.M. Sechenov First Moscow State Medical University (Sechenov University), 8/2 Malaya Trubetskaya St., Moscow, 119991, Russia

The aim of the study was to design a construct based on a nasal septal cartilage plate providing required cell differentiation in different layers to replace a deep osteochondral defect and develop an algorithm of chemical and physical effect sequence to create nonimmunogenic two-layer porous structure with requisite elasto-mechanical properties.

Materials and Methods. The plates derived from porcine nasal septal hyaline cartilage covered by perichondrium were multi-stage treated including freezing, equilibrating in a hypotonic saline solution (type I specimens); trypsinization, point IR-laser effect, re-trypsinization (type II specimens); a stabilizing effect of crosslinking agents — glyceraldehyde/ribose in an acidic medium — washing (type III specimens).

For all type specimens:

1) there were established stability parameters (collagen denaturation temperature using a thermal analysis; and Young's modulus using a mechanical analysis);

2) there were determined morphological characteristics using light and polarization microscopy with classical staining and nonlinear optical microscopy in second-harmonic generation mode.

Results. Thermal, mechanical, and morphological properties in type I specimens slightly differed from those of the initial nasoseptal system. A considerable part of cells had destroyed membranes.

In type II specimens, thermal stability of collagen frame was significantly lower; Young's modulus decreased more than fourfold compared to type I specimens. Collagen structure of hyaline cartilage appeared to be disarranged, although the morphological differences of the hyaline part and perichondrium preserved. The construct matrix was almost completely decellularized. Successive exposure to laser radiation and trypsin resulted in the formation of partial holes in the matrix, $\sim 100 \mu \mathrm{m}$ in diameter.

In type III specimens, both the thermal stability of the collagen frame and Young's modulus (E) increased. Glyceraldehyde was more effective than ribose, E having reached the value typical for intact hyaline cartilage. Collagen fibers in type III specimens were thicker than in type I and II specimens. The morphological differences of the hyaline part and perichondrium and partial holes were preserved.

Conclusion. Due to sequential treatment by salts, trypsin, IR-laser radiation, and nontoxic crosslinking agents, nasal septal cartilage plate forms porous acellular construction consisting of two layers formed by type I (from perichondrium) and type II (from hyaline part) collagen fibers. In the present construction, stability, mechanical properties, and size of the partial holes can be assigned for cell colonization. It enables to use the construction to replace articular cartilage defects.

Key words: porous scaffold; cartilage tissue; chemical modification; glyceraldehyde; ribose.

How to cite: Ignatieva N.Yu., Zakharkina O.L., Sergeeva E.A., Serezhnikova N.B., Faizullin A.L., Shekhter A.B. Development of a two-layer porous scaffold based on porcine nasal septal cartilage for orthopedics. Sovremennye tehnologii v medicine 2021; 13(4): 48, https://doi.org/10.17691/stm2021.13.4.05

This is an open access article under the CC BY 4.0 license (https://creativecommons.org/licenses/by/4.0/).

Corresponding author: Natalia Yu. Ignatieva, e-mail: nyu@kge.msu.ru 


\section{Introduction}

Deep osteochondral defects due to injuries and osteochondrosis present one of the most common problems in locomotion pathology therapy. Over the past two decades, there has been introduced a novel approach to tissue regeneration determining implantation of tissue-engineering constructs [1].

A construct used for an articular cartilage should meet certain requirements [2-5]: 1) to be non-immunogenic, biodegradable, and biocompatible; 2) to be able to be extensionally cell-colonized; 3 ) to preserve the differentiation of chondrocytes or to differentiate in chondrocytes when inoculating scaffold by stem cells; 4) to comply with osteochondral structure by its elastomechanical properties and heterogeneous multi-layer structure.

It is likely that an ideal construct is to be considered the one made from self-tissue (an autograft), however, the approach has a certain restriction: a replacement of a deep osteochondral defect results in defects forming elsewhere. A promising basis for cartilaginous tissue scaffolds is decellularized matrix of animal cartilaginous tissue proper - xenograft [3-13], which complies with requirements 1 and 3 . Decellularization is a multi-stage process of combined chemomechanical treatment [4], after which cartilaginous tissue preparation fails to meet requirement 4 . It should be noted that decellularization without mechanical grinding is rather labor-consuming process; moreover, the remaining collagen matrix appears to be too dense to ensure compliance with requirement 2 [7]. To create material with directed collagen fibers and pores from cartilage powder needs, as a rule, special press molds with programmable temperature change $[8,10,11]$. Another challenging technique to create channels in collagen matrix was suggested in the study [9], where the needles, $400 \mu \mathrm{m}$ in diameter, were used.

One of the most complicated problems in creating a construct replacing an osteochondral defect is related to multilayered damaged tissue of an articular cartilage; its upper part is a hyaline cartilage formed by type II collagen, and lower part is a subchondral bone tissue formed on the basis of type I collagen. Different variants to fabricate a single stable construct satisfying requirement 4 have been suggested; however, most methods are highly technical; among these are spacedivision transgene immobilization encoding different growth factors for chondrogenic or osteogenic stem cell differentiation [14], and mechanical combination of a decellularized ground cartilage and a mineral (or a polymer) subsystem [15-18].

As a primary part for scaffolds, we suggest using a nasal septum part including the hyaline cartilage (type II collagen) and perichondrium (type I collagen). After decellularization and forming pores, and the recovery of collagen framework mechanical properties due to the formation of additional transverse bonds, it is possible to create a supporting construct to replace osteochondral defects meeting requirements $1-4$. It should be noted that partial holes $\sim 100 \mu \mathrm{m}$ in size are considered optimal for free colonization with chondrocytes [9].

The aim of the study was to design a construct based on a nasal septal cartilage plate providing required cell differentiation in different layers to replace a deep osteochondral defect and develop an algorithm of chemical and physical effect sequence to create nonimmunogenic two-layer porous structure with requisite elasto-mechanical properties.

\section{Materials and Methods}

As an initial system, we used the plates, $7 \times 10 \mathrm{~mm}$ in size, and $2 \mathrm{~mm}$ thick, cut out of the porcine nasal septum (not later than $12 \mathrm{~h}$ after sacrifice). The plates were covered by a thin perichondral layer, the bottom was the hyaline cartilage part.

The preliminary treatment was the plates freezing within 6 days at $-18^{\circ} \mathrm{C}$ and subsequent equilibrating for $24 \mathrm{~h}$ at $37^{\circ} \mathrm{C}$ in a hypotonic saline solution $(0.1 \mathrm{M} \mathrm{NaCl}$ with added $0.01 \mathrm{M}$ Tris- $\mathrm{HCl}$ and $0.005 \mathrm{M} \mathrm{MgCl}_{2}$ ).

Enzymatic treatment consisted in incubating the plates for $24 \mathrm{~h}$ at $37^{\circ} \mathrm{C}$ in $\mathrm{NaCl}$ solution, $0.15 \mathrm{M}$, containing trypsin, $1 \mathrm{mg} / \mathrm{ml}$. The treatment was performed twice: before and after IR-laser irradiation.

The crosslinking agent treatment involved incubating the plates within a specified period of time $(24,48$, or $120 \mathrm{~h}$ ) at $24^{\circ} \mathrm{C}$ in $\mathrm{NaCl}$ solution, $0.15 \mathrm{M}$, with $\mathrm{HCl}$ added up to the concentration reaching $0.32 \mathrm{mM}(\mathrm{pH}$ 3.5) containing a crosslinking agent. As a crosslinking agent, we used glyceraldehyde, which formed in situ from its precursor - diethyl acetal of glyceraldehyde in an acidic medium. The precursor was added in the solution so that the concentration was $0.02 \mathrm{M}$. Another crosslinking agent - ribose (concentration $0.02 \mathrm{M}$ ) - was also tested. Such treatments were conducted after IR-laser exposure.

After each treatment (enzymatic treatment and crosslinking agent treatment), the specimens were washed in $300 \mathrm{ml} \mathrm{NaCl}$ solution $0.15 \mathrm{M}$ using a filter funnel under vacuum of a water-jet pump. Washing time of each specimen was about an hour.

To form partial holes in the material, we used erbiumdoped fiber laser radiation, $1.56 \mu \mathrm{m}$ wavelength. Radiation was delivered through a quartz optical fiber, the core diameter being $400 \mu \mathrm{m}$. There was a contact action, the field of incidence diameter corresponded to the fiber diameter. The construct plate was exposed to radiation bilaterally, by laser spot rows; the distance between the rows and two adjacent spots was about $2 \mathrm{~mm}$. At such distance between the spots, the matrix change in each exposure area was due to a direct laser radiation effect at the site fibers contact with the material and does not depend on radiation at adjacent points.

Collagen thermal stability of the specimens was measured by a differential scanning calorimeter 


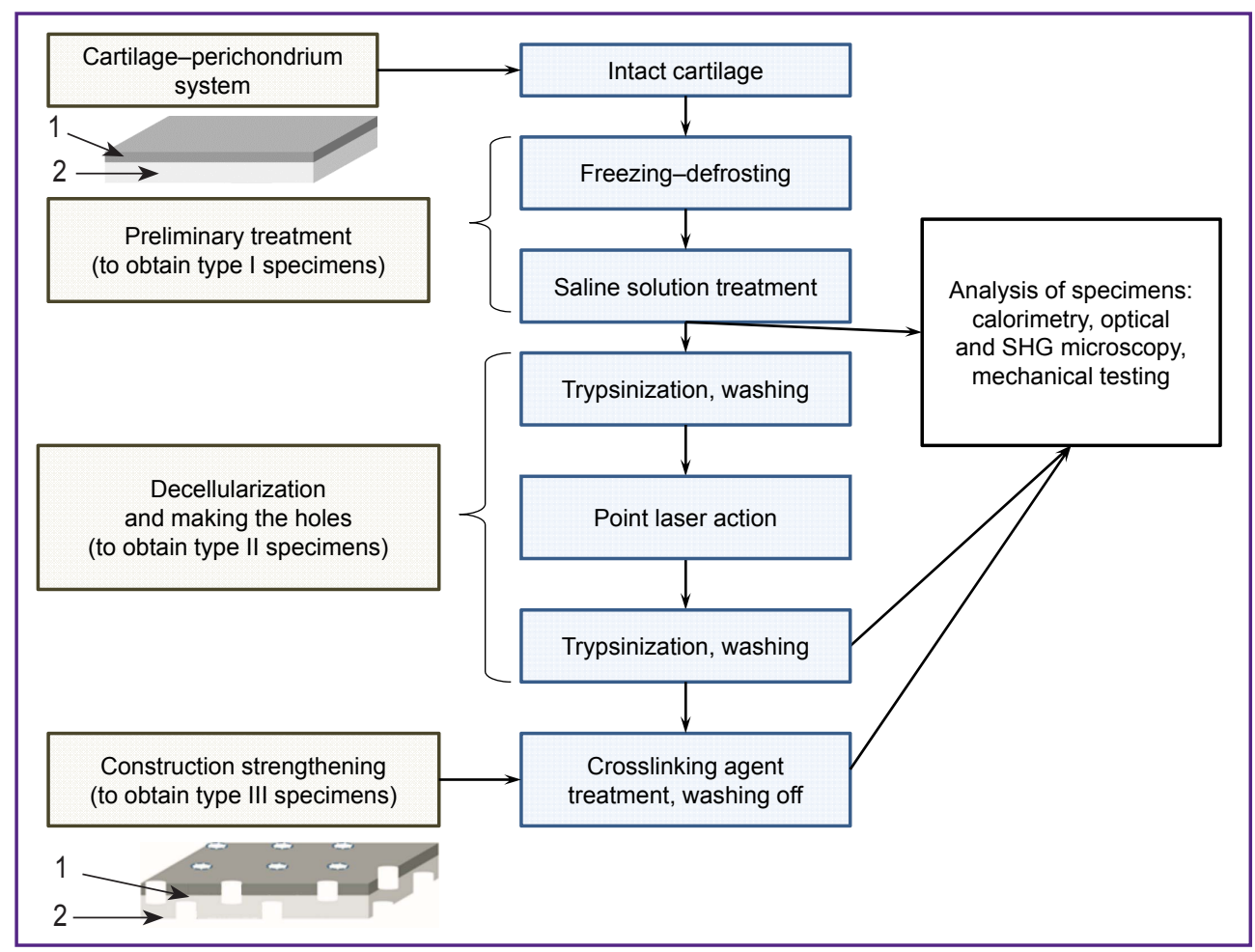

Figure 1. Block diagram of the experiment: 1 - perichondrium; 2 - hyaline cartilage

(model DSC 204 F1; Netzsch, Germany). Specimens weighing $5-8 \mathrm{mg}$ were hermetically sealed in standard aluminum dishes, their volume being $20 \mu \mathrm{l}$. Initial and end temperatures were 20 and $90^{\circ} \mathrm{C}$, respectively; the heating rate was $10 \mathrm{~K} / \mathrm{min}$.

Mechanical testing was conducted using a universal desk testing machine EZ Test (model EZ-SX; Shimadzu, Japan) at room temperature, under the conditions of uniaxial compression in the direction perpendicular to the plate surface. Vertical load (up to $20 \mathrm{H}$ ) was determined using a force-monitoring system, the rate of displacement of the compressing plate was $0.5 \mu \mathrm{m} / \mathrm{s}$. Using automatically recorded data "load-displacement" we derived the relation "stress $(\sigma)$-strain $(\varepsilon)$ ", which was further approximated using the exponential function $\sigma=A \cdot \exp (B \varepsilon)$ with two adjustable parameters $(A, B)$. The first-order derivative value of an approximate function, if $\varepsilon=10 \%$, was taken as Young's modulus (E).

For morphological studies, we fixed the specimens in $10 \%$ neutral formalin, and prepared paraffin sections, 4 and $16 \mu \mathrm{m}$ thick. Thinner sections stained by hematoxylin and eosin and picrosirius red according to a standard technique were studied using a universal optic microscope Leica DM4000 B LED (Leica Microsystems, Switzerland) in the modes of light, phase contrast, and polarization microscopy. Microphotographs were taken using a digital video camera Leica DFC7000 T with LAS V4.8 software. The sections, $16 \mu \mathrm{m}$ thick, were visualized in the second-harmonic generation (SHG) mode and studied using a laser scanning microscope LSM 510 META (Carl Zeiss, Germany). The excitation was carried out by pulse femtosecond radiation of Ti:Sa-laser (Mai Tai HP; Spectra-Physics, USA), wavelength $800 \mathrm{~nm}$, pulse duration $100 \mathrm{fs}$, and pulse repetition rate of $80 \mathrm{MHz}$. SHG signal was separated using a dichroic filter of visible radiation (HFT KP 650; Carl Zeiss) and a narrow-band filter (400/10 nm).

Figure 1 shows the experimental design including the preparation of specimens and the method used to study them.

\section{Results}

A morphological examination of the specimens after the preliminary treatment (type I) showed most chondrocytes to be characterized by cell nuclei deformity and karyorrhexis; collagen matrix structure was preserved both in the hyaline part and in the perichondrium (Figure 2).

A thermal analysis confirmed that collagen in both parts preserved thermal stability: in the hyaline part collagen does not denatures up to $95^{\circ} \mathrm{C}$, and in the perichondrium, denaturation occurs at $63.5 \pm 0.5^{\circ} \mathrm{C}$.

Mechanical properties of type I specimens were no different from intact ones: Young's modulus $(E)$ was $0.65 \pm 0.15 \mathrm{MPa}$ that was close to $\mathrm{E}=0.70 \pm 0.10 \mathrm{MPa}$ typical for intact specimens.

To form partial holes, type I specimens at the first 


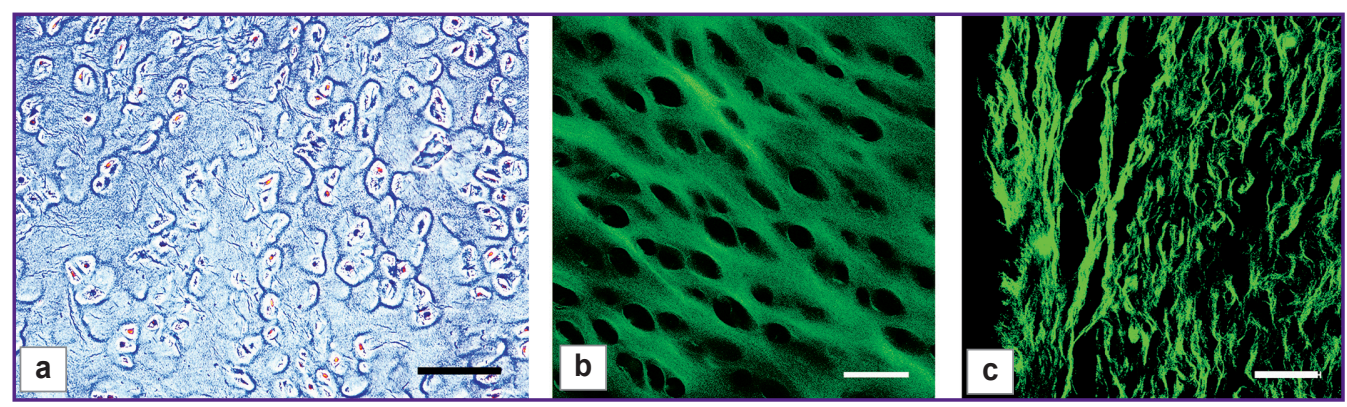

Figure 2. Microphotographs of type I specimen sections:

(a) hyaline cartilage, hematoxylin and eosin staining, phase contrast microscopy; (b) hyaline cartilage;

(c) perichondrium; SHG images. Bar $-50 \mu \mathrm{m}$

Figure 3. Laser openings on transverse (a) and longitudinal (b) sections of type II specimens:

(a) hematoxylin and eosin staining, phase contrast microscopy; (b) SHG image. Bar $-50 \mu \mathrm{m}$
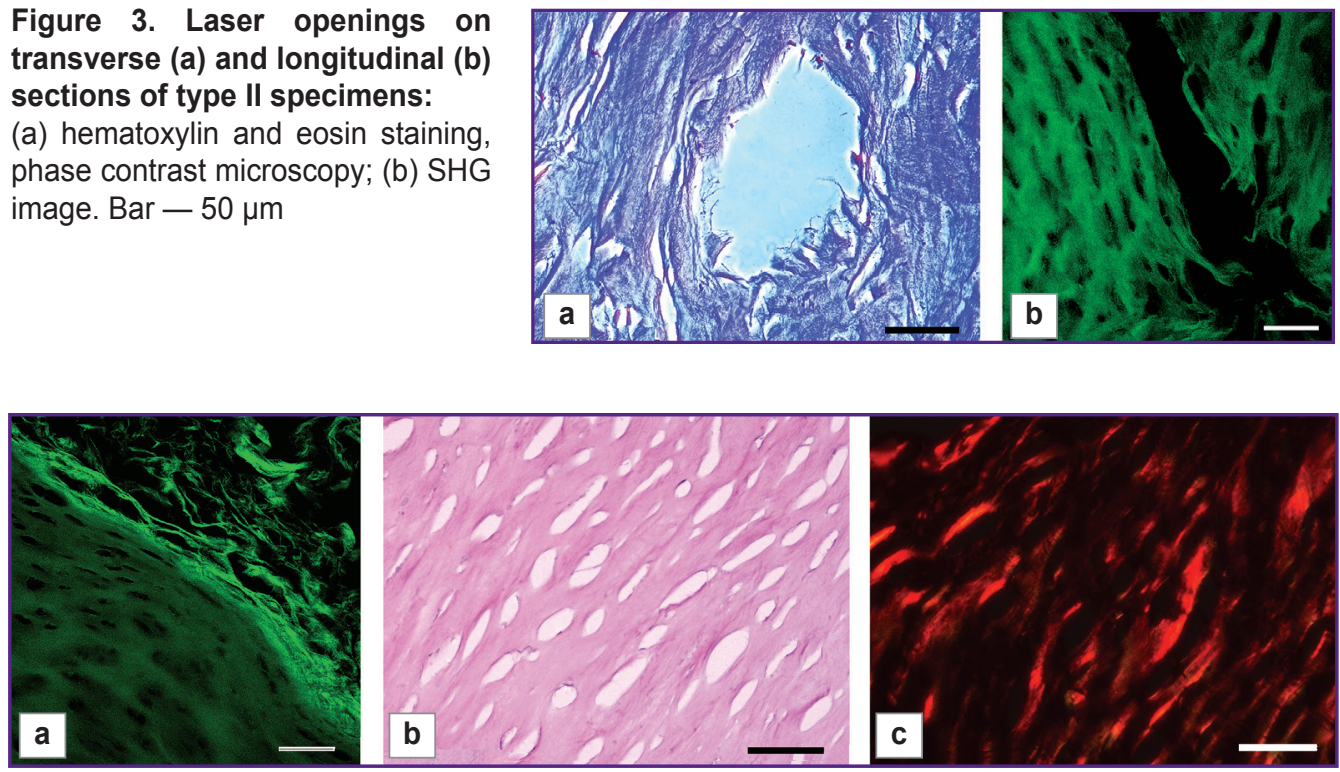

Figure 4. Microphotographs of type II specimen sections:

(a) SHG image; (b) hematoxylin and eosin staining; (c) picrosirius red staining, polarization microscopy. Bar $-50 \mu \mathrm{m}$

stage were enzymatically treated, proteolysis products including glycosaminoglycan chains were washed off. After such procedure, thermal stability of perichondral collagen was unchanged; however, collagen in the hyaline part was able to denature completely at $61.8 \pm 0.5^{\circ} \mathrm{C}$.

Local denaturation requires, on the one hand, laser heating time to be significantly lesser than thermal relaxation time ( 0.1 $\mathrm{s}$ in radial direction [19]), and, on the other hand, the temperature in the object exposed to radiation to be not less than $61^{\circ} \mathrm{C}$. Therefore, there were chosen the pulse durations: 50 and $100 \mathrm{~ms}$, laser radiation power was 2-4 W [20]. After point laser treatment, the specimens were re-trypsinized and washed off from proteolysis products.

Geometric characteristics of the partial holes were measured using a laboratory microscope with the accuracy of about $10 \mu \mathrm{m}$. It turned out that at $2 \mathrm{~W}$ power and pulse duration $100 \mathrm{~ms}$, or $3 \mathrm{~W}$ power and pulse duration $50 \mathrm{~s}$, holes were formed, from 90 to $120 \mu \mathrm{m}$ in diameter, that was close to the target size. In this way, we obtained type II specimens.

The microphotographs of longitudinal and transverse sections of type II specimens show the matrix actually has partial holes formed, their diameter being close to target values: $~ 100 \mu \mathrm{m}$ (Figure 3).

Type II specimens were found to have significant morphological changes compared to type I specimens. The microphotographs show most lacunae be empty, without cell nuclei (karyolysis), only some of them having nuclear fragments (karyorrhexis). Collagen fibers were found in the perichondrium, as well as in the hyaline part; however, the hyaline fibrillar structure was damaged (Figure 4). In normally homogeneous matrix, thin fibrous structure appears, while collagen anisotropy in polarization microscopy occurs not everywhere.

According to the thermal analysis, perichondral collagen stability in type II specimens changed 


\section{BIOTECHNOLOGIES}

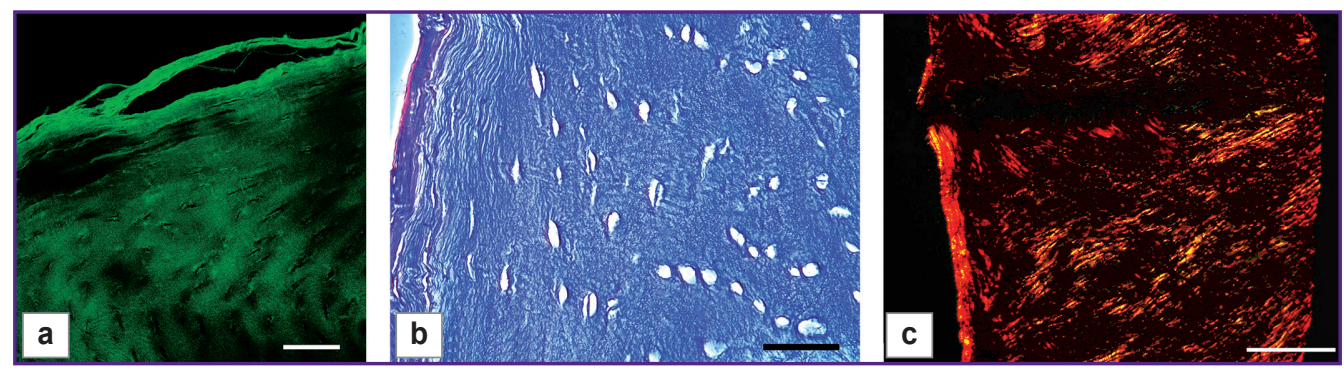

Figure 5. Microphotographs of type III specimen sections after exposure to glyceraldehyde within $48 \mathrm{~h}$ :

(a) SHG image; (b) hematoxylin and eosin staining, phase contrast microscopy; (c) picrosirius red staining, polarization microscopy. Bar $-50 \mu \mathrm{m}(\mathrm{a})$, (b) and $500 \mu \mathrm{m}$ (c)

slightly compared to the hyaline part collagen, where denaturation was within the range $48-61^{\circ} \mathrm{C}$, with maximum peak at endotherm $\sim 55^{\circ} \mathrm{C}$. Young's modulus decreased up to $0.15 \pm 0.10 \mathrm{MPa}$.

Collagen framework was strengthened due to the treatment with crosslinking agents (glyceraldehyde and ribose) resulting in type III specimens, which were characterized by almost total absence of cellular nuclei in preserved collagen framework and laser partial holes (Figure 5). Collagen matrix architectonics of the hyaline part was significantly changed: the structure became denser, the fibers arranging in bundles. The perichondral fibers preserved their orientation, which was parallel to the surface.

Collagen thermal stability in type III specimens increased. Specimen crosslinking time increase resulted in denaturation time growth. Glyceraldehyde as a crosslinking agent appeared to be more active than ribose. Thermal analysis findings of type III specimens are presented in the Table.

Mechanical stability in type III specimens increased, Young's modulus turned out to be close to $E$ value for intact collagen tissue. Similar to denaturation temperature, glyceraldehyde treatment led to greater $\mathrm{E}$ increase compared to ribose, even in lesser exposure

Thermal and mechanical characteristics of the specimens when preparing scaffolds

\begin{tabular}{ccc}
\hline $\begin{array}{c}\text { Specimen } \\
\text { type }\end{array}$ & $\begin{array}{c}\text { Denaturation temperature } \\
\text { of the hyaline part }\left({ }^{\circ} \mathrm{C}\right)\end{array}$ & $\begin{array}{c}\text { Young's modulus } \\
(\mathrm{MPa})\end{array}$ \\
\hline I & $>95$ & $0.65 \pm 0.15$ \\
II & $55 \pm 2$ & $0.15 \pm 0.10$ \\
\hline III GA-24 & $62 \pm 1$ & $0.65 \pm 0.10$ \\
\hline III GA-48 & $64 \pm 1$ & $0.7 \pm 0.1$ \\
\hline III R-48 & $59 \pm 1$ & $0.3 \pm 0.1$ \\
\hline III R-120 & $62 \pm 1$ & $0.6 \pm 0.2$ \\
\hline
\end{tabular}

H e r e: GA - glyceraldehyde; $\mathrm{R}$ - ribose; 24,48 , and 120 - exposure time of a crosslinking agent $(\mathrm{h})$. time. Crosslinking time increase using glyceraldehyde resulted in $\mathrm{E}$ growth. E values for type III specimens are also presented in the Table.

\section{Discussion}

The preparatory treatment of cartilaginous plate had an effect, primarily, on cell condition. Indeed, freezingdefrosting and hypotonic solution treatment initiated cell membrane damage. Thus, the first destruction stage occurred in type I specimens. First trypsinization of type I specimens makes it possible to denature collagen of the hyaline cartilage part in IR-laser heating [21]. As a result, after laser irradiation and re-trypsinization, in its turn launching proteolysis of denatured collagen, partial holes form in preparations. Holes radius and length depend on laser action parameters. Wavelength of radiation $(\lambda)$ determined radiation penetration depth; fiber diameter - a zone of treatment. Pulse duration $(t)$ and power $(P)$ cause maximum temperature, and their variations enable to correct variation range in tissue [22] To form holes, $100 \mu \mathrm{m}$ in radius and $\sim 1 \mathrm{~mm}$ long, we chose $\lambda=1.56 \mu \mathrm{m}$ and an appropriate fiber diameter for contact action. Other required characteristics ( $P$ and $t)$ were determined experimentally: preliminarily, we had assessed their range in previous studies [20]. Thus, changing IR-laser irradiation parameters it is possible to vary geometrical characteristics of the holes in the collagen frame within a rather wide range.

It is significant that double proteolytic enzymatic treatment leading to the destruction of all proteins (including intracellular ones), and double washing of proteolysis products results in almost complete matrix decellularization. Presumably, membrane destruction and DNA and RNA, which are freed from stabilizing protein membranes, contribute to cellular material removing. Unfortunately, collagen frame loses its stability including thermal and mechanical ones, due to the destruction of the proteoglycan aggregate subsystem [21, 23].

Nearly fivefold decrease of Young's modulus in type II specimens puts in question their application to replace 
cartilaginous parts, which are subjected to compression when a joint works. To enhance stiffness and mechanical strength of collagen-based materials, there being successfully used crosslinking agent treatment [2426]. The first agents were multifunctional aldehydes, in primary reaction forming the bonds between an aldol group and a free amino group of lysine residue included in a collagen polypeptide chain [24]. The increase in the number of covalent bonds between collagen molecules is likely to result in stiffness growth of the material consisting of single fibers [27]. The main requirements to crosslinking agents (in particular, aldehydes) are their sufficient chemical activity in addition reaction, on the one hand, and cytotoxicity absence - on the other hand. As crosslinking agents, we chose 2 aldehydes: more active glyceraldehyde with extremely low cytotoxicity, and much less active ribose, which is absolutely noncytotoxic. Both agents exhibited their ability to stabilize the collagen frame of a construct (type III specimens of glyceraldehyde and type III specimens of ribose). Moreover, if reaction time increases, the bridging degree values (denaturation temperature and $\mathrm{E}$ ) grew, however, in compliance with expected activity. Thus, after $24 \mathrm{~h}$ of glyceraldehyde action, mechanical characteristics of the material were equal to those for the initial hyaline cartilage. Collagen became significantly more thermostable. As for active ribose, which is less chemically active, we managed to reach the target value after three-day reaction. Thus, the use of nontoxic crosslinking agents enables to obtain scaffolds based on an integrated system of collagen II and I fibers, primarily, divided in space, the mechanical characteristics of a construct can be varied in a wide range.

We carried out the reactions leading to crosslinking formed between macromolecules at $\mathrm{pH} 3.5$, in contrast to the studies [25-28], which also used these crosslinking agents. It is impossible to use an acidic medium for in vivo crosslinking, however, for scaffold treatment, it is not a barrier, since excess acid can be neutralized by the base or washed off. On the other hand, the formation of the first covalent bond between aldehyde and lysine residue involves protonation stage and a reaction in an acidic medium proceeds considerably faster. Indeed, in a neutral medium, it is possible to achieve significant changes of stability characteristics under ribose action within 5-7 days [25-28]. In our case, the effect was achieved as early as in 3 days.

The essential result is the preservation of a single collagen frame and hyaline part represented by collagen II, and perichondrium chiefly consisting of collagen I. Such spatial division of different types of collagen in a uniform system can provide necessary differentiation in both osteogenic and chondrogenic parts.

\section{Conclusion}

Due to sequential treatment by salts, trypsin, IRlaser radiation, and nontoxic crosslinking agents, nasal septal cartilage plate forms porous acellular construction consisting of two layers formed by type I (from perichondrium) and type II (from hyaline part) collagen fibers. In the present construction, stability, mechanical properties, and size of the cavities can be assigned for cell colonization. It enables to use the construction to replace articular cartilage defects.

Study funding. The study was supported by Russian Foundation for Basic Research (grants No.19-0200135a and No.19-315-90058), as well as the Ministry of Science and Higher Education of the Russian Federation as part of State Task of Federal Research Center "Crystallography and Photonics", Russian Academy of Sciences so far as it relates laser technologies, Federal Research Center Institute of Applied Physics, Russian Academy of Sciences (project No.0030-2021-0014) as far as it relates the morphological study and State Task on the project No.AAAA-A21-121011990019-4 in the part concerning physicochemical modification and analysis of specimens.

Conflicts of interest. The authors have no conflicts of interest related to the present study.

\section{References}

1. Cheng A., Schwartz Z., Kahn A., Li X., Shao Z., Sun M., Ao Y., Boyan B.D., Chen H. Advances in porous scaffold design for bone and cartilage tissue engineering and regeneration. Tissue Eng Part B Rev 2019; 25(1): 14-29, https://doi.org/10.1089/ten.teb.2018.0119.

2. Wang M., Yuan Z., Ma N., Hao C., Guo W., Zou G., Zhang Y., Chen M., Gao S., Peng J., Wang A., Wang Y., Sui X., Xu W., Lu S., Liu S., Guo Q. Advances and prospects in stem cells for cartilage regeneration. Stem Cells Int 2017; 2017: 4130607, https://doi.org/10.1155/2017/4130607.

3. Izadifar Z., Chen X., Kulyk W. Strategic design and fabrication of engineered scaffolds for articular cartilage repair. J Funct Biomater 2012; 3(4): 799-838, https://doi.org/10.3390/ jfb3040799.

4. Cheng C.W., Solorio L.D., Alsberg E. Decellularized tissue and cell-derived extracellular matrices as scaffolds for orthopaedic tissue engineering. Biotechnol Adv 2014; 32(2): 462-484, https://doi.org/10.1016/j.biotechadv.2013.12.012.

5. Yang Q., Peng J., Guo Q., Huang J., Zhang L., Yao J., Yang F., Wang S., Xu W., Wang A., Lu S. A cartilage ECM-derived 3-D porous acellular matrix scaffold for in vivo cartilage tissue engineering with $\mathrm{PKH} 26$-labeled chondrogenic bone marrow-derived mesenchymal stem cells. Biomaterials 2008; 29(15): 2378-2387, https://doi.org/10.1016/j. biomaterials.2008.01.037.

6. Zhang Y., Liu S., Guo W., Wang M., Hao C., Gao S., Zhang X., Li X., Chen M., Jing X., Wang Z., Peng J., Lu S., Guo Q. Human umbilical cord Wharton's jelly mesenchymal stem cells combined with an acellular cartilage extracellular matrix scaffold improve cartilage repair compared with microfracture in a caprine model. Osteoarthritis Cartilage 2018; 26(7): 954-965, https://doi.org/10.1016/j.joca.2018.01.019.

7. Graham M.E., Gratzer P.F., Bezuhly M., Hong P. Development and characterization of decellularized human nasoseptal cartilage matrix for use in tissue engineering. 
Laryngoscope 2016; 126(10): 2226-2231, https://doi. org/10.1002/lary.25884.

8. Jia S., Zhang T., Xiong Z., Pan W., Lui J., Sun W. In vivo evaluation of a novel oriented scaffold-BMSC construct for enhancing full-thickness articular cartilage repair in a rabbit model. PLoS One 2015; 10(12): e0145667, https://doi. org/10.1371/journal.pone.0145667.

9. Luo R., Eswaramoorthy K.J., Mulhall D.J., Kelly D.J. Decellularization of porcine articular cartilage explants and their subsequent repopulation with human chondroprogenitor cells. J Mech Behav Biomed Mater 2015; 55: 21-31, https:// doi.org/10.1016/j.jmbbm.2015.10.002.

10. Bowland P., Ingham E., Jennings L., Fisher J. Review of the biomechanics and biotribology of osteochondral grafts used for surgical interventions in the knee. Proc Inst Mech Eng H 2015; 229(12): 879-888, https://doi. org/10.1177/0954411915615470.

11. Wang K.H., Wan R., Chiu L.H., Tsai Y.H., Fang C.L., Bowley J.F., Chen K.C., Shih H.N., Lai W.T. Effects of collagen matrix and bioreactor cultivation on cartilage regeneration of a fullthickness critical-size knee joint cartilage defects with subchondral bone damage in a rabbit model. PLoS One 2018; 13(5): e0196779, https://doi.org/10.1371/journal. pone.0196779.

12. Rowland R., Colucci L.A., Guilak F. Fabrication of anatomically-shaped cartilage constructs using decellularized cartilage-derived matrix scaffolds. Biomaterials 2016; 91: 5772, https://doi.org/10.1016/j.biomaterials.2016.03.012.

13. Baranovsky D.S., Demchenko A.G., Oganesyan R.V., Lebedev G.V., Berseneva D.A., Balyasin M.V., Parshin V.D., Lyundup A.V. Acellular tracheal cartilaginous scaffold producing for tissue-engineered constructs. Vestnik Rossiiskoi akademii medetsinskikh nauk 2017; 72(4): 254-260, https:// doi.org/10.15690/vramn723.

14. Rowland C.R., Glass C.A., Ettyreddy A.R., Gloss C.C., Matthews J.R.L., Huynh N.P.T., Guilak F. Regulation of decellularized tissue remodeling via scaffold-mediated lentiviral delivery in anatomically-shaped osteochondral constructs. Biomaterials 2018; 177: 161-175, https://doi.org/10.1016/j. biomaterials.2018.04.049.

15. Yang Q., Peng J., Lu S.B., Guo Q.Y., Zhao B., Zhang L., Wang A.Y., Xu W.J., Xia Q., Ma X.L., Hu Y.C., $\mathrm{Xu}$ B.S. Evaluation of an extracellular matrix-derived acellular biphasic scaffold/cell construct in the repair of a large articular high-load-bearing osteochondral defect in a canine model. Chin Med J (Engl) 2011; 124(23): 3930-3938.

16. Hernigou ${ }_{\text {. }}$. Vertongen P., Chahidi E., Kyriakidis T., Dehoux J.P. Crutzen M., Boutry S., Larbanoix L., Houben S. Gaspard N., Koulalis D., Rasschaert J. Effects of press-fit biphasic (collagen and HA/ $\beta T C P$ ) scaffold with cell-based therapy on cartilage and subchondral bone repair knee defect in rabbits. Intern Orthop 2018; 42(7): 1755-1767, https://doi.org/10.1007/s00264-018-3999-3.

17. Bernhardt A., Pauk B., Gelinsky M. Biphasic scaffolds from marine collagens for regeneration of osteochondral defects. Mar Drugs 2018; 16(3): 91-97, https://doi.org/10.3390/ md16030091.

18. Xu Y., Guo X., Yang Sh., Li L., Zhang P., Sun W., Liu C., Mi S. Construction of bionic tissue engineering cartilage scaffold based on three-dimensional printing and oriented frozen technology. J Biomed Mater Res Part A 2018; 106(6): 1664-1676, https://doi.org/10.1002/jbm.a.36368.

19. Zakharkina O.L., Sergeeva E.A., Kirillin M.Yu., Ignatieva N.Y. Analysis of laser-induced modification of collagen structure using nonlinear optical microscopy. Quantum Electron 2020; 50(1): 76-80, https://doi.org/10.1070/ qel17214.

20. Sviridov A.P., Zakharkina O.L., Ignatieva N.Y., Vorobieva N.N., Bagratashvili N.V., Plyakin V.A., Kulik I.O., Sarukhanyan O.O., Minaev V.P., Lunin V.V., Bagratashvili V.N. Ex vivo laser thermoplasty of whole costal cartilages. Lasers Surg Med 2014; 46(4): 302-309, https://doi.org/10.1002/ Ism.22233.

21. Ignatieva N.Yu., Lunin V.V., Averkiev S.V., Maiorova A.F., Bagratashvili V.N., Sobol E.N. DSC investigation of connective tissues treated by IR-laser radiation. Thermochim Acta 2004; 422(1-2): 43-48, https://doi.org/10.1016/j.tca.2004.04.030.

22. Lazernaya inzheneriya khryashchey [Cartilage laser engineering]. Bagratashvili V.N., Sobol E.N., Shekhter A.B. (editors). Moscow: FIZMATLIT; 2006.

23. Schmidt M.B., Mow V.C., Chun L.E., Eyre D.R. Effects of proteoglycan extraction on the tensile behavior of articular cartilage. J Orthop Res 1990; 8(3): 353-363, https://doi. org/10.1002/jor.1100080307.

24. Bailey A.J., Paul R.G., Knott L. Mechanisms of maturation and ageing of collagen. Mech Ageing Dev 1998; 106(1-2): 1-56, https://doi.org/10.1016/s0047-6374(98) 00119-5.

25. Danilov N.A., Ignatieva N.Yu., lomdina E.N., Semenova S.A., Rudenskaya G.N., Grokhovskaya T.E., Lunin V.V. Stabilization of scleral collagen by glycerol aldehyde cross-linking. Biochim Biophys Acta 2008; 1780(5): 764-772, https://doi.org/10.1016/j.bbagen.2008.01.014.

26. Sung H.W., Chang Y., Chiu C.T., Chen C.N., Liang H.C. Crosslinking characteristics and mechanical properties of a bovine pericardium fixed with a naturally occurring crosslinking agent. J Biomed Mater Res 1999; 47(2): 116-126, https:// doi.org/10.1002/(sici)1097-4636(199911)47:2<116::aidjbm2>3.0.co;2-j.

27. Bai P., Phua K., Hardt T., Cernadas M., Brodsky B. Glycation alters collagen fibril organization. Connect Tissue Res 1992; 28(1-2): 1-12, https://doi. org/10.3109/03008209209014224.

28. Lee K.W., Simpson G., Ortwerth B. A systematic approach to evaluate the modification of lens proteins by glycation-induced crosslinking. Biochim Biophys Acta 1999; 1453(1): 141-151, https://doi.org/10.1016/s0925-4439(98) 00097-0. 